\title{
More evidence of robust spatial associative memory in the pigeon, Columba livia
}

\author{
DONALD M. WILKIE \\ University of British Columbia, Vancouver, British Columbia, Canada \\ and \\ ROBERT J. WILLSON \\ University of Oxford, Oxford, England
}

\begin{abstract}
Willson and Wilkie (1993) developed a novel procedure for assessing pigeons' memory for the spatial location of food. Only one of four locations (consisting of an illuminated pecking key and grain feeder) provided food each day. Over days, different locations provided food. The pigeons' tendency to revisit the location that was profitable on the previous day demonstrated memory for food-spatiallocation associations over a period of $24 \mathrm{~h}$, retention longer than previously reported for this species. This basic finding was replicated and extended in three experiments. Experiment 1 demonstrated that location-food discriminations were also remembered well when established with successive rather than concurrent procedures. Experiment 2 demonstrated that pigeons can remember two location-food associations over $24 \mathrm{~h}$. Experiment 3 showed that the discrimination training inherent in this paradigm is important for retention; retention was impaired when only the rewarded location was presented. Overall, this research suggests that cross-species differences in spatial memory performance may be due to quantitative rather than qualitative differences in the memory system underlying performance.
\end{abstract}

We have recently developed a new procedure to study pigeons' spatial memory (Willson \& Wilkie, 1993). Development of this task was motivated by the persistent reporting of rather short-lived spatial memory in pigeons tested on a variety of spatial memory tasks (e.g., delayed alternation-Olson \& Maki, 1983; radial maze-Roberts \& Van Veldhuizen, 1985; walking maze - Spetch, 1990; delayed matching-Wilkie \& Summers, 1982; keypeck analogue of the radial maze Zentall, Steirn, \& Jackson-Smith, 1990). The often short-lived memory in this species stands in contrast to that reported for several species of food-caching birds (e.g., Sherry, 1984). However, an examination of the tasks on which pigeons' spatial memory has been assessed reveals that they are all working memory tasks (Honig, 1978). In contrast, food-caching birds are thought to use a spatial-location-food associative memory to locate their caches (Brodbeck, Burack, \& Shettleworth, 1992; Shettleworth, 1985; but see Olson, 1991, for a direct comparison between pigeons and food-storing birds on a working memory task). Spatial associative

This research was supported by the Natural Sciences and Engineering Research Council of Canada. R.J.W. is now at the Department of Psychology, St. Andrews University, Fife, Scotland. Send correspondence concerning this article to D. M. Wilkie, Department of Psychology, University of British Columbia, Vancouver, BC, Canada V6T 1Z4 (e-mail: dwilkie@,cortex.psych.ubc.ca). memory has not been examined in pigeons, so we therefore developed a task to do so.

The task is straightforward. Pigeons are tested in a large, clear Plexiglas box placed on a table in a well-lit room containing a variety of visual cues. A key and grain feeder are located on each of the four walls of the box. Sessions are short (approximately $16 \mathrm{~min}$ ) and consist of illumination of all four keys, only one of which (randomly selected) produces response-contingent food. Food becomes available on the selected key after the passage of a brief interval at the start of the session. Pigeons quickly discover the rewarded key and persist in responding to that location during the initial nonrewarded period of the next session, even when sessions are separated by $72 \mathrm{~h}$ (Willson \& Wilkie, 1993). This perseverative responding in the face of extended delays is evidence of a robust memory for spatial-locationfood associations.

The purpose of the present research was to provide more information about pigeons' spatial associative memory. In the Willson and Wilkie (1993) study, the four keys were concurrently available. Another way of arranging the task is to present the four keys successively, again having only one randomly selected key provide food each day. For example, during a particular session, the keys may appear in the order 1, 4, 3, 2, with Key 2 providing food, whereas in another session, the keys may appear in the order $3,1,4,2$, with Key 3 providing food. Would location-food information be acquired and retained under such successive 
arrangements? This question was the focus of Experiment 1.

Food-caching birds, which are also thought to use spatial associative memory (Brodbeck et al., 1992), remember many locations over extended retention intervals. In the Willson and Wilkie (1993) study, pigeons remembered the location of only one profitable location. The focus of Experiment 2 was whether or not pigeons could remember more than one profitable location over 24 -h retention intervals.

Finally, a central idea in the concept of spatial associative memory is that subjects discriminate between locations associated with food and those that are not. It follows, then, that this memory ability should be impaired if such discriminations are not formed. Some evidence of such an effect was reported by Willson and Wilkie (1991) in a study of delayed matching of spatial location. In that study, pigeons remembered spatial location samples better when the rewarded sample and nonrewarded distractor locations were presented during the study phase of a matching trial than when only the rewarded sample was presented. The purpose of Experiment 3 was to determine whether the absence of explicit discrimination training would likewise impair spatial associative memory.

\section{EXPERIMENT 1}

Our procedures for studying pigeons' spatial associative memory are similar to both standard discrimination learning and matching-to-sample procedures, although they differ in significant ways from both (cf. Willson \& Wilkie, 1991, 1993). In successive matching to sample (SMTS; Konorski, 1959; Wasserman, 1976), a sample is presented for a brief interval, extinguished, and followed, after a brief retention interval, by a stimulus that either matches or does not match the sample. Responses to the matching stimuli are reinforced, whereas responses to nonmatching stimuli are not. The procedure developed by Willson and Wilkie (1993) is similar to SMTS in that memory for the most recently reinforced location is inferred by measuring the pigeons' tendency to "match" (i.e., respond at the location most recently associated with reward). This procedure is also similar to SMTS in that (1) the sample is typically drawn from a small pool of stimuli, (2) the identity of the sample varies from trial to trial, and (3) the sample can also serve as a distractor on other trials. The procedure differs from SMTS in that there is no differential reinforcement of responding to the most recently rewarded sample (memory assessment is actually conducted in extinction).

In successive discrimination procedures, subjects are exposed to several different stimuli within each session, only some of which are followed by reward. The relationship between stimuli and reinforcement remains the same from session to session, and learning is measured in terms of the subjects' tendency to respond to stimuli associated with reward and to withhold responding to stimuli followed by nonreward. Willson and Wilkie's (1993) procedure is similar in that subjects are exposed to several stimuli within a session, some of which are associated with reward, some of which are not. However, it differs because the relationship between the various stimuli and reinforcement changes from session to session.

Successive discrimination procedures have often been used to study concept learning (for a review, see Herrnstein, 1984), and recent work by Macphail and his colleagues (Macphail \& Reilly, 1989; Macphail, Reilly, \& Good, 1992; see also Todd \& Mackintosh, 1990) is relevant to the current work. Macphail and his colleagues studied whether pigeons could acquire a concept of novelty (i.e., learn to respond to novel visual stimuli and withhold responses to familiar visual stimuli). The subjects in Macphail and Reilly's (1989) experiment quickly learned this procedure but showed an initial tendency to respond more to familiar slides than to novel slides. Further work demonstrated that this tendency was due to the formation of associations between the slides and reinforcement (Macphail et al., 1992). Furthermore, Macphail et al. (1992) showed that these associations, formed after only a single pairing of a particular slide and food, continued to influence performance $24 \mathrm{~h}$ later.

In the present experiment, we sought evidence that pigeons could acquire and retain spatial-location-food associations when the locations were encountered successively. However, to facilitate the comparison of performance on the successive and simultaneous versions of this spatial memory task, retention performance was assessed by using a brief simultaneous presentation of the four spatial locations at the start of each session, a procedure identical to one we have used previously (see Willson \& Wilkie, 1993, for details).

\section{Method}

Subjects. The subjects were 3 homing pigeons that were maintained in large plastic coated wire mesh cages, where they had free access to vitamin-fortified water (Nekton-K), granite grit, and crushed oyster shells. The colony was climate controlled $\left(20^{\circ} \mathrm{C}\right)$ and had a light:dark photoperiod matched to the natural sunrise: sunset times. The experiment proper was conducted 5 days per week at about 10:00 between June 2, 1993 (sunrise at 04:11 and sunset at 20:10) and August 10,1993 (sunrise at 04:58 and sunset at 19:38).

The subjects had been trained previously to peck keys for food reinforcement in a different type of apparatus but were naive with respect to the present procedures. Each subject was fed a sufficient amount of mixed grain each day to maintain its body weight at approximately $95 \%$ of free-feeding weight.

Apparatus. The pigeons were tested in one of two similar large square Plexiglas chambers (see Willson \& Wilkie, 1993, for details). A 3.5-cm-diameter key was mounted on the center of each wall, $20 \mathrm{~cm}$ above the floor. Behind each key was a microswitch that sensed pecks having a force greater than $0.15 \mathrm{~N}$, and a $28-\mathrm{V} \mathrm{dc}$ GE No. 313 lamp covered by a red gelatin filter. A standard grain feeder was mounted directly below each key. The chambers were located in small (about $2 \times 2 \mathrm{~m}$ ), well-lit testing rooms. The subjects could see a variety of room cues (window, door, etc.) through the transparent walls of the boxes. 
Data collection and experimental control were carried out by the MANX language (Gilbert \& Rice, 1979) running on a minicomputer.

Procedure. Because the subjects had previous keypeck training, little preliminary training was required. The subjects initially received a few sessions in which pecks to each of the four keys, presented one at a time, were reinforced with grain.

In the experiment proper, each subject received 40 sessions, each of which was divided into two phases. In the initial phase, all four keys were lit and pecks were recorded, but no food was available. The initial period was initiated by the first peck at any key and lasted an average of $45 \mathrm{sec}$ (the probability was .25 that the initial period would end after each 15 -sec interval). This variableinterval arrangement was intended to encourage responding during this nonrewarded period by preventing the subjects from anticipating when the nonrewarded period would end and the rewarded period would begin. This initial period was employed to see whether subjects persevered in responding to the key that had provided food during the previous session, conducted approximately $24 \mathrm{~h}$ earlier (or longer over weekends).

The second phase of each session lasted 64 min. During this phase, only one key (randomly selected with no restrictions) was lit at a time. Moreover, only one key (randomly selected with no restrictions) provided food each day according to an intermittent schedule. For the rewarded key, the probability of 5-sec access to mixed grain was .166 at the end of each $10-\mathrm{sec}$ interval. Each of the four keys was lit for $16 \mathrm{~min}$. As an example of such a session, Key 2 may be selected to provide food and this key may be illuminated during the third $16-\mathrm{min}$ period. Food is unavailable during the first 16-min period when Key 4 is illuminated, during the second 16-min period when Key 1 is illuminated, and during the final 16-min period when Key 3 is illuminated.

During each session, a discrimination ratio was calculated for responding during the initial no-food period. The total number of pecks made to the key that had provided food on the previous day was divided by the total number of pecks made to all four keys during this period. This ratio measures subjects' tendency to persevere on the key that was rewarded on the previous day and serves as an index of the subjects' ability to remember place-food associations from day to day. In the absence of such memory, this discrimination ratio would be expected to have a value of 0.25 .

\section{Results and Discussion}

Figure 1 shows discrimination ratios, plotted as "proportion correct," averaged over the 39 usable sessions for each subject. These ratios are significantly greater than chance [one-sample $t(2)=13.13, p=.0057$ ] and replicate the main finding reported by Willson and Wilkie (1993)-namely, that pigeons return to a location at which food had been found at least $24 \mathrm{~h}$ earlier. This finding again clearly demonstrates that pigeons remember food-location associations over considerable temporal intervals after only a few reinforcements (an average of approximately 14). The results also clearly demonstrate that such memory performance is not dependent on a simultaneous discrimination of food location. The levels of performance on the successive discrimination are quite comparable to those reported by Willson and Wilkie (1993) on a simultaneous discrimination task. Furthermore, these results replicate the findings of Macphail et al. (1992) showing 24-h retention of stimulus-outcome associations by pigeons, and they extend the generality of that finding into the spatial domain.

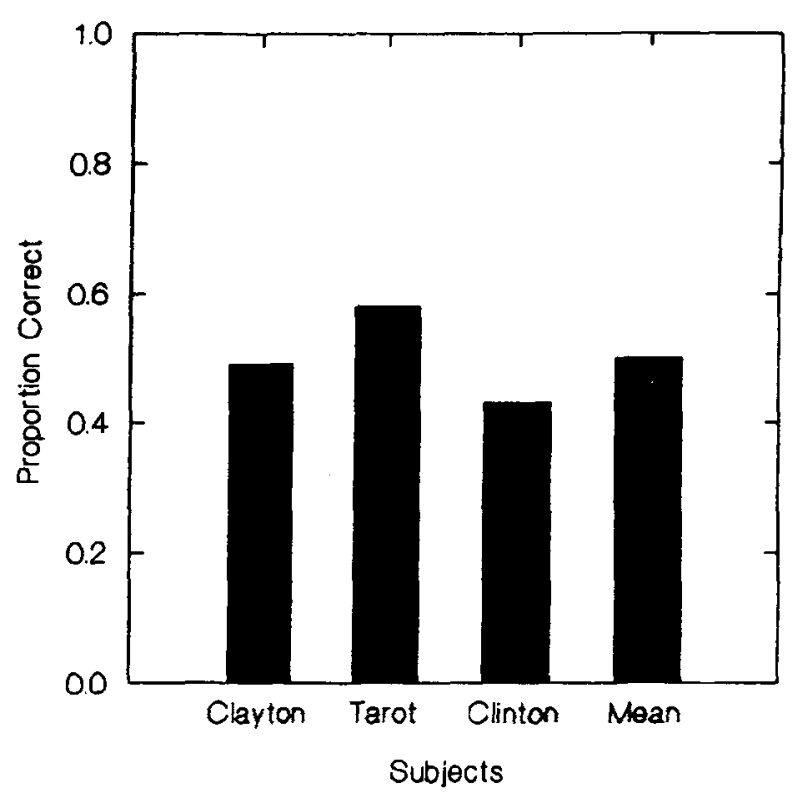

Figure 1. Proportion of pecks during the initial nonrewarded period of each session that were directed at the key location that had provided food during the previous session.

The data were also examined for evidence of a serial position effect (better memory performance when the rewarded key appeared first or last in a session). There was no clear evidence of such an effect. Indeed, different subjects exhibited different patterns of performance: Subject Clayton performed best for Position 2, next best for Position 4, third best for Position 3, and fourth best for Position 1 (i.e., 2, 4, 3, 1). The order for Subject Tarot was 1, 3, 4, 2, and for Subject Clinton, 3, 2, 1, 4 .

\section{EXPERIMENT 2}

The results of Experiment 1, in conjunction with our previous findings (Willson \& Wilkie, 1993) clearly demonstrate that pigeons possess a robust memory for spatiallocation-food associations and that these associations are formed within 16 or fewer minutes, irrespectively of whether the stimuli are encountered successively or simultaneously.

Shettleworth (1985) has suggested that spatial associative memory might be the mechanism by which foodstoring birds relocate their caches, and Brodbeck et al. (1992) have demonstrated that food storers demonstrate a robust memory for spatial location and food. Our own results suggest that pigeons possess a similar mechanism that could be used to return to profitable feeding sites in the wild.

However, in Experiment 1, our subjects were required to recall only a single positive location (see Healy \& Krebs, 1992, for an experiment comparing a storing and a nonstoring species on their ability to recall a single positive location). In the wild, food-storing birds are thought to recall the location of numerous different 
cache sites, and the possibility exists that differences in spatial memory performance on this type of task would only be detected when subjects are required to recall multiple sites.

Macphail et al. (1992) demonstrated that pigeons could retain 20 briefly trained slide-outcome associations for a period of $24 \mathrm{~h}$, and Vaughan and Greene (1984) demonstrated that pigeons can retain hundreds of slide-outcome associations for extended periods of time when they are exposed to a consistent relationship between a particular slide and a particular outcome on multiple occasions. In Experiment 2, then, we sought evidence that pigeons could also retain multiple spatiallocation-food associations.

\section{Method}

Subjects and Apparatus. The same subjects as tested in Experiment 1 (plus a 4th homing pigeon that had background experience and preliminary training similar to that of the other subjects) served in this experiment. The apparatus was the same as in Experiment 1.

Procedure. The experiment was conducted on 60 days between January 14, 1993 (sunrise at 08:03, sunset at 16:41) and April 21, 1993 (sunrise at 05:22, sunset at 19:03). The subjects received two sessions each day. The first session was conducted at about 10:00 in a Plexiglas chamber located on a table top in the center of a well-lit $1.5 \times 1.8 \mathrm{~m}$ room (Room 1 ). This room contained many prominent features which, when one faced the front of the room and viewed it in a clockwise direction, consisted of an orange door, a beige wall with a poster, a plain beige wall, a concrete post, and a curtained window. The second session was conducted in a slightly smaller chamber in a second room of identical size (Room 2). The prominent cues in the latter room, as one faced the front and viewed them in a clockwise direction, consisted of an orange door, a one-way mirrored window, a concrete post, and two plain beige walls. Each session lasted $16 \mathrm{~min}$. The second session was conducted about 1-2 min after the completion of the first session. In both sessions, all four keys were concurrently lit, and one key/feeder location was randomly selected each day to provide food on the same intermittent schedule as that in Experiment 1. Both sessions started after the first peck was made and had the same initial nonrewarded period as in Experiment 1.

\section{Results and Discussion}

The results of this experiment are given in Figure 2, which shows the discrimination ratio (proportion correct) of pecks to the key that had provided food during the previous day's session in both Room 1 (left bar) and Room 2 (right bar). All subjects persevered to the previous day's rewarded location in both rooms to approximately the same extent. One-sample $t$ tests confirmed that the discrimination ratios were significantly above chance in both Room $1[t(3)=5.71, p=.011]$ and Room $2[t(3)=12.92, p=.001]$. There was no evidence of any transfer of learning between rooms (i.e., that the pigeons pecked the key location in Room 2 that was correct in Room 1).

The results of this experiment, then, clearly demonstrate that pigeons are capable of retaining multiple spatial-location-food associations for periods of $24 \mathrm{~h}$ or more. Healy and Krebs (1992) found no difference between marsh tits and blue tits-storing and nonstoring

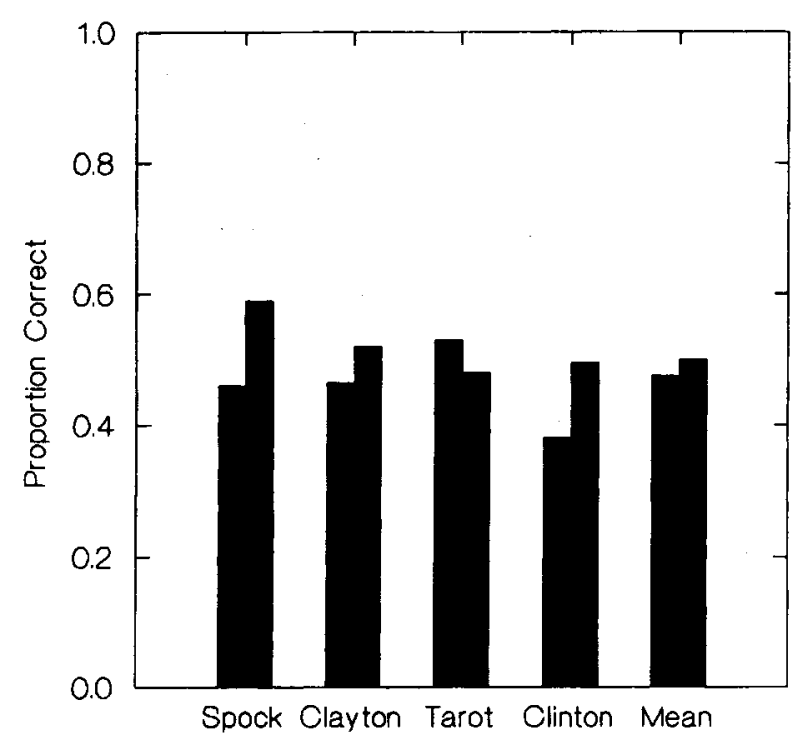

Subjects

Figure 2. Proportion of pecks during the initial nonrewarded period of each session that were directed at the key location that had provided food during the previous session in Room 1 (left bar) and Room 2 (right bar).

members, respectively, of the parid family - on their ability to retain the location of a single site associated with reinforcement, although performance did approach chance levels as the retention interval approached $24 \mathrm{~h}$. Healy and Krebs suggested that differences might only be detected if the ability to recall multiple sites was tested. Although there is obviously a difference between recalling the location of two sites and recalling the location of hundreds of sites, our results nevertheless demonstrate that pigeons can recall more than a single spatiallocation-food association.

Spetch (1990) found no evidence that memory load influenced pigeons' performance on a spatial working memory task (at least not within the load limits that she tested), although overall performance was at chance levels with retention intervals of only $2 \mathrm{~h}$. This finding, in conjunction with our finding of multiple-item memory ability in the pigeon, suggests that between-species differences in performance on spatial associative memory tasks may be due to quantitative rather than qualitative differences in the memory system underlying performance.

\section{EXPERIMENT 3}

The purpose of this experiment was to examine the role of explicit discrimination training in pigeons' tendency to persevere to a location that had provided food one day earlier. In both the simultaneous and the successive versions of the present paradigm, one randomly selected location provides food, whereas three other locations do not. In one condition in Experiment 3, only 
the "correct," or rewarded, location was presented for 16 min (i.e., no explicit discrimination training between rewarded and nonrewarded sites was provided). In the next session, all four keys were briefly presented in order to examine the subjects' tendency to persevere to the location that had provided food in the previous session. On the basis of results reported by Willson and Wilkie (1991), it was expected that retention would be impaired by the absence of explicit discrimination training.

\section{Method}

Subjects and Apparatus. The apparatus was the same as that used in Experiments 1 and 2. The subjects were 4 pigeons that had received prior keypeck training in this apparatus.

The subjects were tested at about 10:00 between January 5, 1994 (sunrise at 08:07 and sunset at 16:29) and March 30, 1994 (sunrise at 05:54 and sunset at 18:40).

Procedure. The subjects first received approximately 25 sessions identical to those in Experiment 2 (except that the pigeons received only one 16-min session in one room). The subjects then received approximately an additional 25 sessions in which the session began as usual (all four keys lit, a response-initiated variable period in which pecking on the four keys was recorded). After this initial recording period, only the correct, rewarded key was lit for the remainder of the 16-min session. Thus, in the latter phase of the experiment, the subject did not have to search for the rewarded location or to discriminate rewarded locations from nonrewarded locations.

\section{Results and Discussion}

Figure 3 shows discrimination ratios, plotted as proportion correct, averaged over the last 20 sessions in both discrimination (left bars) and nondiscrimination conditions (right bars). All subjects performed more poorly when a discrimination between rewarded and nonrewarded locations was not required. This drop in performance was confirmed statistically $[t(3)=4.14$, $p=.026]$. The pigeons did not remember the previous day's rewarded location as well during single-key sessions despite the fact that they obtained slightly more reinforcers in these sessions (an average of approximately 15 as compared to an average of approximately 14 in the regular discrimination sessions). Although performance in the single-key condition was not statistically different from chance $[t(3)=1.61, p=.21], 3$ of the 4 pigeons seemed to remember the previous day's rewarded location (i.e., performed at better than a chance level of .25).

The present results systematically replicate the results of Willson and Wilkie (1991) and add confidence to our conclusion that discrimination training enhances retention. In the Willson and Wilkie study, pigeons remembered spatial location samples in a delayed matching-to-sample task better when the sample study period consisted of a rewarded sample-nonrewarded distractor discrimination than when the sample study period consisted of only a rewarded sample.

\section{GENERAL DISCUSSION}

The results of these experiments replicate and extend those reported by Willson and Wilkie (1993) and demon-

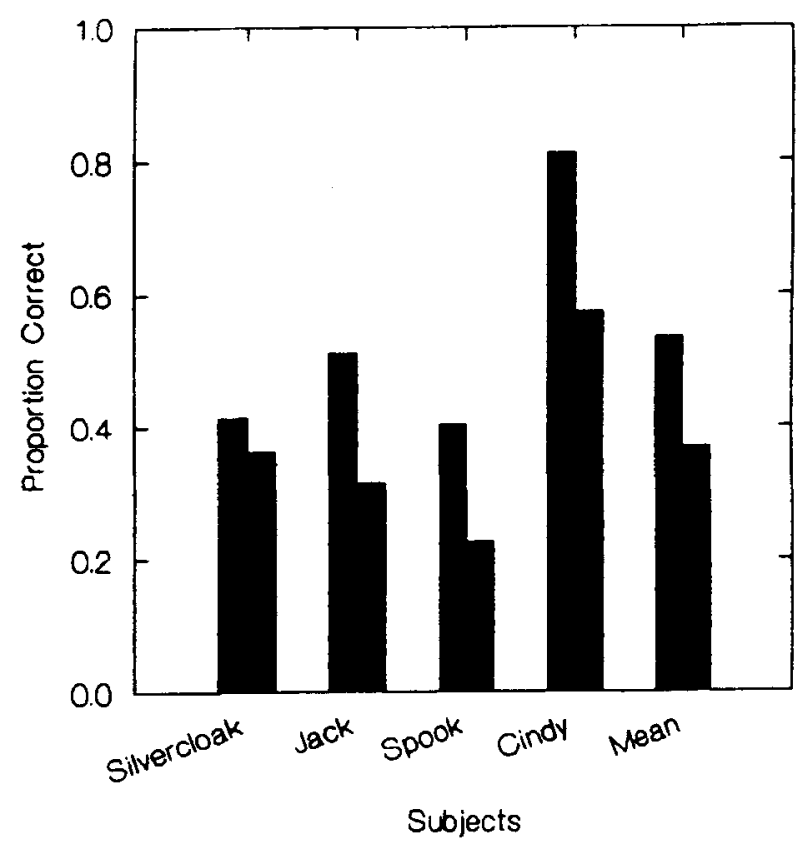

Figure 3. Proportion of pecks during the initial nonrewarded period of each session that were directed at the key location that had provided food during the previous session in sessions in which discrimination training was given (left bar) and in sessions in which no discrimination training was given (right bar).

strate that pigeons remember food-spatial-location associations over periods of at least $24 \mathrm{~h}$. They also stand in remarkable contrast to the much less robust retention typically found in studies in which pigeons' working memory for spatial location is assessed (e.g., Olson \& Maki, 1983; Roberts \& Van Veldhuizen, 1985; Spetch, 1990; Wilkie \& Summers, 1982; Zentall et al., 1990; however, see Shettleworth \& Plowright, 1989, and Willson \& Wilkie, 1991, for exceptions). The results extend previous findings in two directions.

First, the results from Experiment 1 show that pigeons persevere to a rewarded location learned during a successive discrimination task in which possible food locations are encountered one after the other. There are considerable differences between the simultaneous and successive tasks. In the simultaneous discrimination task, subjects quickly switch back and forth between keys and typically discover the rewarded location within a couple of minutes. In the successive task, there is no opportunity to "sample" the various locations and quickly discover which location is rewarded. Furthermore, the rewarded location sometimes will not be encountered until $48 \mathrm{~min}$ after the start of the session. The finding that subjects perform comparably on both tasks is an important indication of the generality of the associative memory process. We have previously shown that discrimination training facilitates remembering in a delayed matching-to-sample task (Willson \& Wilkie, 1991). The results of Experiment 3 show that discrimination training enhances the retention of information in 
the current paradigm. Overall, the present results suggest that discrimination training - and not the details of how that training is administered-is important for robust memory performance. It should be emphasized that in both the simultaneous and successive variants of the food-location memory task subjects received only brief (about $16 \mathrm{~min}$ ) pairing of location with food.

The second way in which the results of the present experiments extend our previous findings is that it is now clear that pigeons are capable of remembering more than one food-place association learned each day. Despite the considerable similarity of the two test rooms (orange door, beige walls, concrete pillar, Plexiglas test chambers, etc.), performance was well above chance in both locations. Three of the 4 pigeons seemed to remember the second learned association slightly better than the first association. However, the opposite pattern was true for the 4th subject, and in all cases, the difference in performance in the two locations was relatively small. These findings are similar to those observed by Willson (unpublished data) in an interference experiment using marsh tits, a food-storing member of the parid family. $\mathrm{He}$ found that marsh tits remembered the location of a hidden peanut even when they were allowed to discover, and partially consume, a peanut hidden in a different but highly similar room.

Finding that pigeons are capable of remembering more than one food-place association is important in linking the pigeon memory literature to the literature on food-caching birds. It is well known that many foodcaching birds remember the location of multiple sites of cached food. And it has recently been suggested that these birds use an associative memory system to locate their caches (Brodbeck et al., 1992). Although we currently have no evidence that pigeons may remember an equivalent large number of food-location associations, we do know that pigeons can remember multiple slidefood associations (Macphail et al., 1992; Vaughan \& Greene, 1984), and this knowledge, together with our own finding, suggests that differences in performance on spatial associative memory tasks may be due to quantitative rather than qualitative differences in the memory system underlying performance.

Finally, given the 24- $\mathrm{h}$ and longer retention intervals in these experiments, it seems that food-spatial-location associative memory is much more durable than working memory, at least in pigeons. This difference is in some ways surprising, because food-place associative memory has some similarity with working memory: In a delayed matching-to-sample working memory task, subjects must recall which of a small set of sample stimuli have most recently appeared; in a food-place associative memory task, subjects must recall which of a small set of food-place associations have been recently formed or, more likely it would seem, strengthened. Apparently, food-place associations are more readily retained than spatial location samples. Yet samples, because they are followed by food on correct matching trials, are probably also associated with food (albeit indirectly). What may be important for the associative-working memory difference is the nature of the association between place and food. In delayed matching of key location, the various sample locations are equally associated with food in each session; in the food-spatial-location associative memory task, locations are differentially associated with food in a session (see Willson \& Wilkie, 1991, for a similar argument). Thus, information that is differentially associated with food seems more easily remembered than information that is nondifferentially associated with food. In other words, it may be the nature of the association that is important for remembering.

\section{REFERENCES}

Brodbeck, D. R., Burack, O. R., \& Shettleworth, S. J. (1992). One-trial associative memory in black-capped chickadees. Journal of Experimental Psychology: Animal Behavior Processes, 18, 12-21.

GILberT, S. G., \& RICE, D. C. (1979). NOVA SKED II: A behavioral notation language utilizing the Data General Corporation real-time disk operating system. Behavioral Research Methods \& Instrumentation, 11, 71-73.

HeALY, S. D., \& KREBS, J. R. (1992). Comparing spatial memory in two species of tit: Recalling a single positive location. Animal Learning \& Behavior, 20, 121-126.

HeRrNStein, R. J. (1984). Objects, categories, and discriminative stimuli. In H. L. Roitblat, T. G. Bever, \& H. S. Terrace (Eds.), Animal cognition (pp. 233-261). Hillsdale, NJ: Erlbaum.

HonIG, W. K. (1978). Studies of working memory in the pigeon. In S. H. Hulse, H. Fowler, \& W. K. Honig (Eds.), Cognitive processes in animal behavior (pp. 211-248). Hillsdale, NJ: Erlbaum.

KONORSKI, J. A. (1959). A new method of physiological investigation of recent memory in animals. Bulletin de l'Academie Polonaise des Sciences: Series des Sciences Biologiques, 7, 115-119.

MACPHAIL, E. M., \& REILLY, S. (1989). Rapid acquisition of a novelty versus familiarity concept by pigeons (Columba livia). Journal of Experimental Psychology: Animal Behavior Processes, 15, 242-252.

MacPhall, E. M., ReILly, S., \& GooD, M. (1992). Long-term memory of pigeons for stimulus-outcome associations involving multiple stimuli, each seen in a single brief trial. Quarterly Journal of Experimental Psychology, 45B, 81-98.

OLson, D. J. (1991). Species differences in spatial memory among Clark's nutcrackers, scrub jays and pigeons. Journal of Experimental Psychology: Animal Behavior Processes, 17, 363-376.

OLSON, D. J., \& MAKI, W. S. (1983). Characteristics of spatial memory in pigeons. Journal of Experimental Psychology: Animal Behavior Processes, 9, 266-280.

Roberts, W. A., \& VAN Veldhuizen, N. (1985). Spatial memory in pigeons on the radial-arm maze. Journal of Experimental Psychology: Animal Behavior Processes, 11, 241-260.

SHERRY, D. F. (1984). What food storing birds remember. Canadian Journal of Psychology, 38, 304-321.

SHETTLEWORTH, S. J. (1985). Food storing by birds: Implications for comparative studies of memory. In N. H. Weinberger, J. L. McGaugh, \& G. Lynch (Eds.), Memory systems of the brain: Animal and human cognitive processes (pp. 231-250). New York: Guilford Press.

Shettleworth, S. J., \& Plowright, C. M. S. (1989). Time horizons of pigeons on a two-armed bandit. Animal Behaviour, 37, 610-633.

SPETCH, M. L. (1990). Further studies of pigeons' spatial working memory in the open-field task. Animal Learning \& Behavior, 18, 332-340.

TODD, I. A., \& MACKInTosh, N. J. (1990). Evidence for perceptual learning in pigeons' recognition memory for pictures. Quarterly Journal of Experimental Psychology, 42B, 385-400.

Vaughan, W., Jr., \& Greene, S. L. (1984). Pigeon visual memory capacity. Journal of Experimental Psychology: Animal Behavior Processes, 10, 256-271. 
WasSerman, E. A. (1976). Successive matching-to-sample in the pigeon: Variations on a theme by Konorski. Behavior Research Methods \& Instrumentation, 8, 278-282.

WilkIE, D. M., \& Summers, R. J. (1982). Pigeons' spatial memory: Factors affecting delayed matching of key location. Journal of the Experimental Analysis of Behavior, 37, 45-56.

WILLSON, R. J., \& WILKIE, D. M. (1991). Discrimination training facilitates pigeons' performance on one-trial-per-day delayed matching of key location. Journal of the Experimental Analysis of Behavior, 55, 201-212.

Willson, R. J., \& Wilkie, D. M. (1993). Pigeons remember briefly trained spatial location-food associations over extended periods of time. Journal of Experimental Psychology: Animal Behavior Processes, 19, 373-379.

Zentale, T. R., Steirn, J. N., \& Jackson-Smith, P. (1990). Memory strategies in pigeons' performance of a radial-arm maze analog task. Journal of Experimental Psychology: Animal Behavior Processes, $16,358-371$.

(Manuscript received November 19, 1993; revision accepted for publication May 10, 1994.) 